\title{
Jazidas de rochas silicosas na área do Parque Nacional Serra da Capivara (Piauí, Brasil): primeiros dados geoarqueológicos
}

\author{
Vittorio Rioda* \\ Federica Candelato** \\ Leidiana Mota*** \\ Fabio Parenti*
}

\begin{abstract}
RIODA, V.; CANDELATO, F.; MOTA, L.; PARENTI, F. Jazidas de rochas silicosas na área do Parque Nacional Serra da Capivara (Piauí, Brasil): primeiros dados geoarqueológicos. R. Museu Arq. Etn., São Paulo, n. 21, p. 103-113, 2011.
\end{abstract}

Resumo: Nos artefatos líticos do Nordeste do Brasil são identificados diferentes tipos de matéria-prima silicosa, o que torna fundamental a caracterização petrográfica dessas rochas. As pesquisas desenvolvidas no abrigo da Pedra Furada levantaram questões acerca da economia da matéria-prima no Sudeste do Piauí, nos períodos do Pleistoceno e Holoceno. Porém, nenhum estudo geoarqueológico e petrográfico havia sido feito sobre os possíveis afloramentos das rochas trabalhadas na pré-história. Portanto, o objetivo desse trabalho é expor os métodos e os resultados preliminares do estudo das fontes de matérias-primas silicosas presentes nos afloramentos rochosos e nos depósitos sedimentares distribuídos na área do Parque Nacional Serra da Capivara (PARNA) e de seu entorno. Busca-se também relacionar as amostras coletadas ao instrumentário lítico de alguns sítios arqueológicos importantes para a região.

Palavras-chave: Rochas silicosas - Indústrias líticas - Sudeste do Piauí Georqueologia.

\section{Introdução e problemática regional}

$\mathrm{O}$ s sertões do Nordeste brasileiro constituem um dos mais ricos acervos de sítios arqueológicos da América do Sul. A região

(*) Istituto italiano di Paleontologia Umana, Roma, Itália. Parenti<scriptoriumparentii@gmail.com>

$\left.{ }^{(* *}\right)$ Università degli Studi di Verona, Itália.

${ }^{(* *)}$ Erasmus Mundus Master em Quaternário e Pré-história. apresenta diferentes tipos de sítios, tais como abrigos, grutas e sítios ao ar livre preservados devido a múltiplas condições favoráveis: clima semi-árido, escassez de intervenções antrópicas e morfologia do relevo. Esta última, especificadamente, favorece tanto a formação de abrigos sob rocha erodidos nas encostas dos extensos tabuleiros sedimentares da Era Primária, quanto o soerguimento, por erosão diferencial do entorno, de morros e serrotes carbonáticos do Pré-Cambriano, que posteriormente sofreram múltiplos 
ciclos de karstificação, com formação de grutas e sumidouros. Essas cavidades são armadilhas sedimentares que contêm grandes quantidades de vestígios fósseis e marcos paleoambientais. Já as extensas planícies do escudo metamórfico Arqueano, erodidas a partir do Mioceno, hospedam milhares de lagoas e cacimbas, que tanto hoje como no passado são as principais reservas hídricas durante as crises de aridez.

Assim, a pesquisa pré-histórica no Nordeste do Brasil tem de integrar dados procedentes de sequências sedimentares em abrigos (com sedimentos ácidos e sem fauna), grutas calcárias e cacimbas fossilíferas, fora os assentamentos de superfície a céu aberto, extremamente difíceis de se datar. Todos esses sítios, quando frequentados pelos grupos pré-históricos, conservam grandes quantidades de artefatos líticos, obtidos de muitos tipos de rochas e com diferentes propriedades de lascamento.

Na Europa a Arqueologia do Paleolítico tem se baseado tradicionalmente na análise de sequências datadas de indústrias líticas, que tem a tipologia como instrumento analítico principal. No estudo das fases mais antigas da pesquisa pré-histórica da América do Sul, em muitos casos este método tem se revelado ilusório: a grande estabilidade técnica durante milênios e, talvez, a escassa importância do instrumentário lítico na cultura material desses grupos tem feito da tipologia lítica uma ferramenta de fraca utilidade para a compreensão do comportamento do homem em relação ao meio ambiente. Entretanto, as definições morfológicas e a tecnologia lítica são necessárias, mas não suficientes para a análise das relações entre sítios diferentes e elaboração de sequências confiáveis.

Na pré-história do Nordeste as matérias-primas diferentes do sílex têm uma importância particular (Araujo e Pugliese 2009) e por essa razão é fundamental a caracterização petrográfica e, consequentemente, a definição terminológica das rochas em questão. No caso do Sudeste do Piauí é preciso salientar que a pesquisa no abrigo da Pedra Furada, referência para a região (Guidon et al. 1994; Parenti 2001; Martin 2005), levantou dois problemas relacionados com a matéria-prima: 1) ausência, nas camadas pleistocênicas, de rochas exógenas ao abrigo como sílex e calcedônia; 2) dificuldade de identificar com precisão a fonte de procedência dessas últimas nos níveis Serra talhada e Agreste do Holoceno. O primeiro ponto está diretamente relacionado à polêmica sobre a antiguidade e autenticidade dos instrumentos líticos da fase pleistocênica Pedra Furada, enquanto o segundo é fonte de ambiguidades terminológicas e, por consequência, da impossibilidade de detectar precisamente a relação entre os grupos humanos e o território na primeira metade do Holoceno.

Por essas razões decidimos abordar o estudo do instrumentário lítico de uma área arqueologicamente tão importante como o Sudeste do Piauí também do ponto de vista geoarqueológico e petrográfico. Por consequência, o objetivo deste trabalho é ilustrar os métodos e os resultados preliminares do estudo das matérias-primas silicosas presentes nos afloramentos rochosos e nos depósitos sedimentares distribuídos na área do Parque Nacional Serra da Capivara (PARNA) e de seu entorno, relacionando-os ao instrumentário lítico de alguns sítios arqueológicos importantes para a região e para o contexto da pré-história brasileira (Araujo 1991; Martin 2005).

\section{Critérios de amostragem e métodos de coleta}

Apesar de mais de mil e trezentos sítios (arqueológicos e paleontológicos) cadastrados na área do PARNA, muitos dos quais contêm rico acervo lítico, até então não existe nenhum estudo sobre as fontes das rochas trabalhadas na pré-história desta região. Os métodos utilizados para este estudo consistem na prospecção, no eventual levantamento geológico de áreas selecionadas, na amostragem, numa primeira descrição macroscópica dos materiais coletados, na análise petrográfica, micro-estrutural e, no caso, micro-paleontológica e geoquímica (Tabela 1). Os materiais são comparados com os manufatos pré-históricos e todos os dados vêm integrados num SIG apósito.

A amostragem dos aluviões quaternários segue a coleta sistemática e a análise estatística dos seixos silicosos em áreas associadas a sítios arqueológicos. O estudo considera quatro categorias principais: as rochas dos instrumentos líticos, as rochas silicosas 


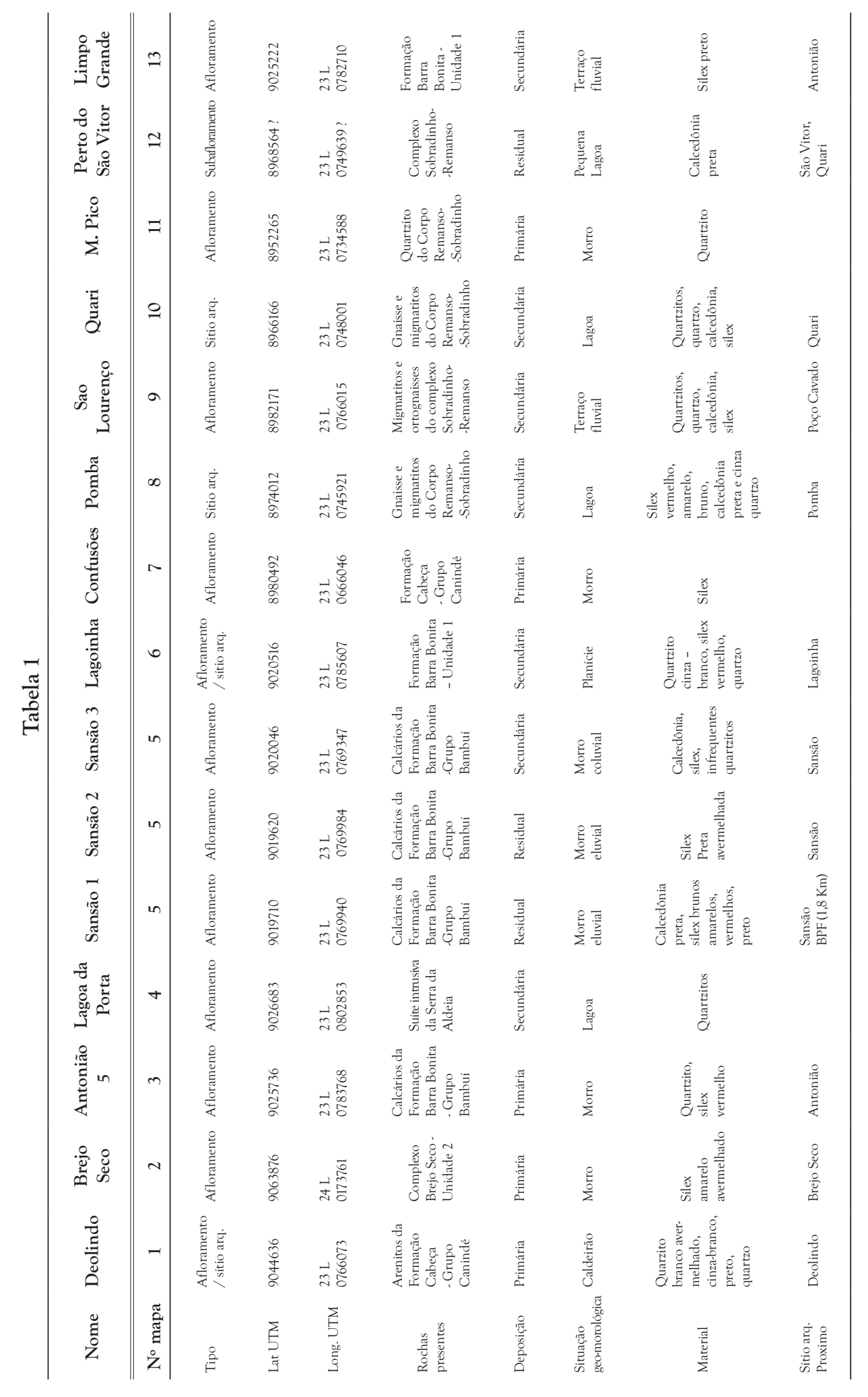


Jazidas de rochas silicosas na área do Parque Nacional Serra da Capivara (Piauí, Brasil): primeiros dados geoarqueológicos. R. Museu Arq. Etn., São Paulo, n. 21, p. 103-113, 2011.

em afloramento (depósitos primários), os clastos silicosos nos depósitos aluviais quaternários (depósitos secundários) e as rochas de origem residual (silcrete ferruginosa). Atualmente a área de pesquisa compreende aproximadamente $8.000 \mathrm{~km}^{2}$ no entorno da Serra da Capivara, abrangendo o Morro do Brejo Seco a Nordeste e a porção mais oriental da Serra das Confusões a Noroeste, chegando até o Morro do Pico a Sul, próximo à fronteira com o Estado da Bahia (Fig. 1).

Nesta primeira fase do trabalho foi feita a coleta de amostras petrográficas em função dos principais tipos de sítios da região, ou seja, diferentes tipos de afloramentos: a Lagoa do Quari como exemplo de jazida fossilífera e arqueológica na planície do substrato Pré-Cambriano, o Poço Cavado (Riacho São Lourenço) para os muitos sítios a céu aberto próximos à drenagem do Rio Piauí, os maciços calcários tanto pelas jazidas em ambiente kárstico neles contidas quanto pela proximidade dos principais abrigos no arenito aos quais forneceram rochas para lascamento, a Serra do Gongo pela proximidade aos sítios do interior do Parque, longe das encostas meridionais e dos maciços calcários.

\section{Afloramentos analisados e contexto arqueo- lógico}

\subsection{Os afloramentos secundários da planície} Pré-Cambriana: Lagoa do Quari e Riacho São Lourenço

A Lagoa do Quari (Fig. 1: 10, UTM: 23 L 7480018966166 ) é uma pequena bacia obtida por erosão do embasamento cristalino e preenchida a partir do Pleistoceno Superior por um depósito de argilas, areias e seixos que contém rica fauna pleistocênica na parte basal da sequência e indústria lítica lascada na superfície (Parenti et al. 2003; Chaves et al. 2008). Em 2003, durante a escavação da missão

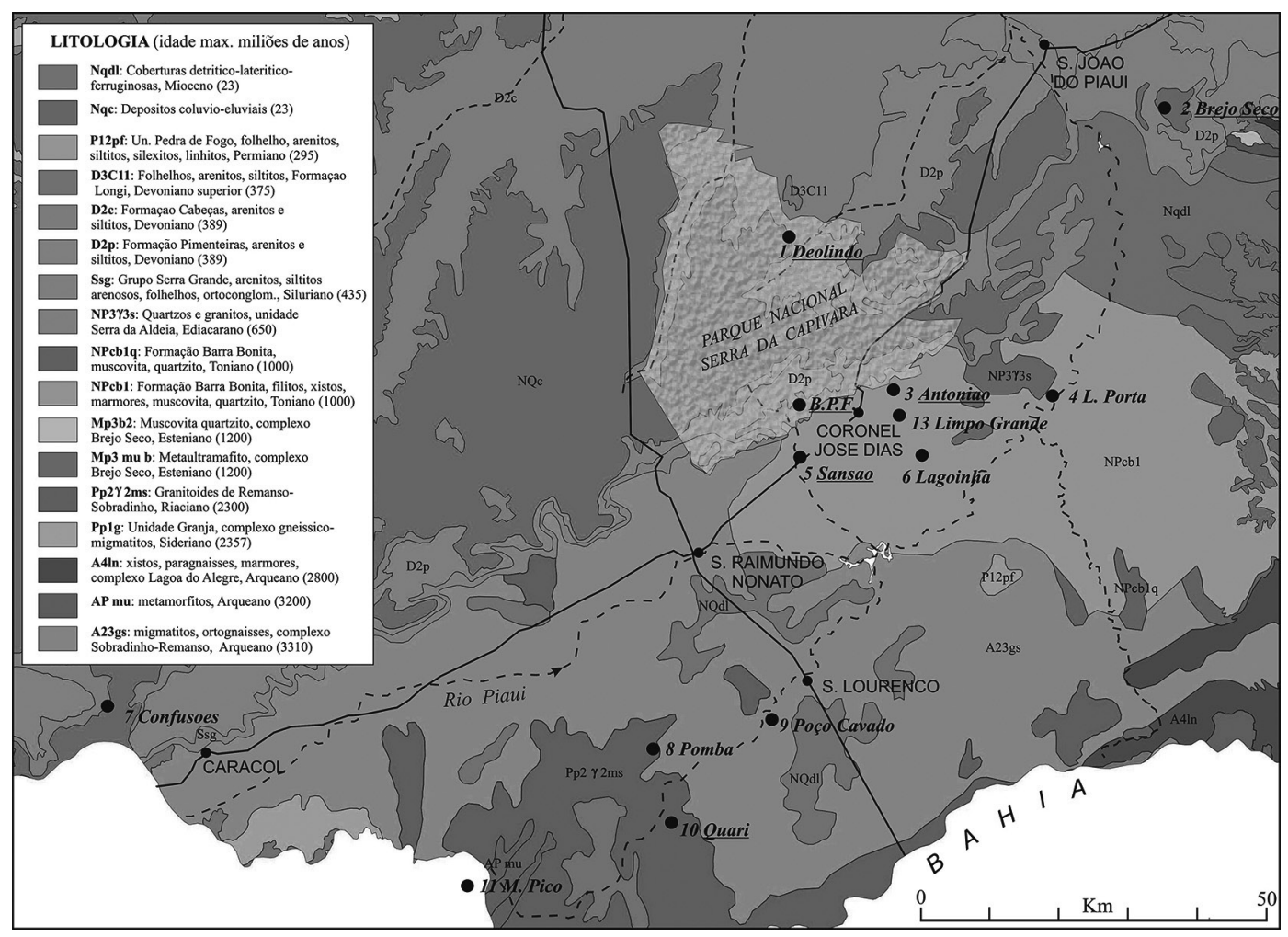

Fig. 1. Mapa litológico e de sítios. 

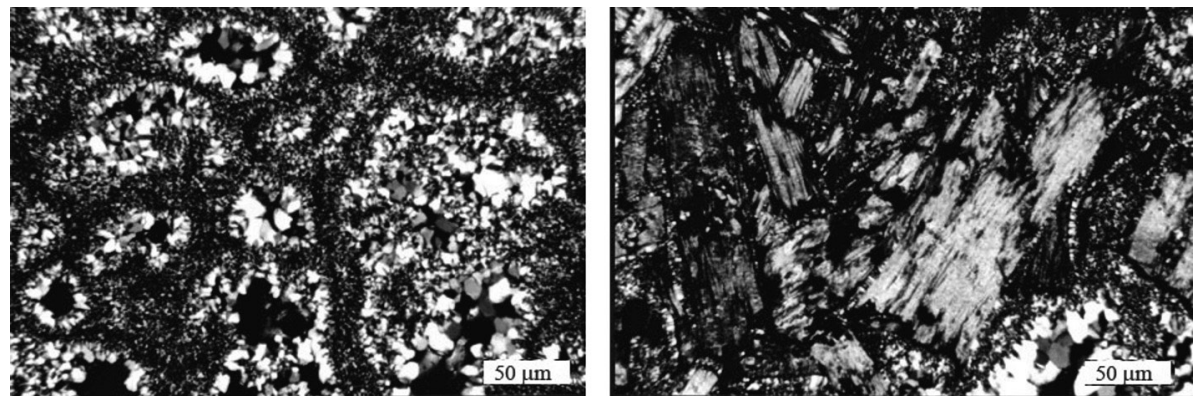

Fig. 2. Microfilme de lâmina delgada.

ítalo-brasileira, foram encontradas, na parte de cima da camada argilosa superior, algumas centenas de peças líticas de diferentes tipos de rochas: quartzito, quartzo, calcedônia, sílex, gnaisse. O levantamento geológico de detalhe e o estudo das rochas do entorno do sítio, cujo embasamento é constituído de gnaisse e migmatitos de metamorfismo regional (Corpo Remanso-Sobradinho-2300-2050 Ma - período Riaciano), apontam para uma origem alóctone de todos os materiais, com exceção do gnaisse, que constitui o substrato da área. (As indústrias da Lagoa do Quari serão ilustradas em detalhe em uma monografia em curso de realização.

Para uma melhor caracterização dos materiais líticos foram realizadas algumas lâminas delgadas de seixos não trabalhados. As análises petrográficas mostram várias fases de alteração das rochas pré-existentes (ex. Migmatitos e gnaisses) com transformação em rochas silicosas e, portanto, indicam uma origem secundária da calcedônia encontrada no sítio (Fig. 2).

A ausência de afloramentos rochosos primários com características parecidas com os líticos da Lagoa do Quari nos obriga a buscar fontes primárias de rochas silicosas na região.

Um outro exemplo de depósito secundário são os terraços do Riacho São Lourenco, onde encontra-se a pequena oficina lítica de Poço Cavado, (Fig. 1: 9; UTM 23 L 766015 8982171). O substrato da área é constituído de migmatitos e ortognaisses das fácies anfibolito-xisto-verde do complexo Sobradinho-Remanso-3300-2800 Ma - Paleo-Meso Arqueano. Ao longo de 400 $\mathrm{m}$ de curso do riacho foram registradas três ordens de terraços fluviais (Fig. 3). Os dois terraços mais antigos continham carvões vegetais que foram datados com o $14 \mathrm{Ce}$ deram respectivamente idades não calibradas de 7810 \pm 70 anos AP (Beta 242137) e $4950 \pm 50$ anos AP (Beta 242136). ${ }^{1}$ Em cima do terraço mais recente, ou seja, no leito atual do riacho (que não foi possível datar), foi encontrada a oficina lítica (Fig. 4) que, portanto, é mais recente que 4950 anos AP. Os instrumentos líticos estavam concentrados numa barra aluvial composta de muitos seixos arredondados, onde claramente foram escolhidos e trabalhados os seixos com grandes dimensões e tendo como matéria-prima principal o sílex.

Os instrumentos coletados apresentam-se bastante frescos e, portanto, foram considerados trabalhados in situ. No laboratório as peças foram descritas arqueologicamente (dimensões, peso, tipo) e as características petrográficas foram observadas mesoscopicamente. ${ }^{2}$ Os traços principais dessa indústria, bastante homogênea por sua situação topográfica e características técnicas, são resumidas na Tabela 2 .

No mesmo terraço foram escolhidas duas áreas de 5 X $5 \mathrm{~m}$ onde se coletaram todos os materiais silicosos presentes, de mais de $5 \mathrm{~cm}$, ou seja, o tamanho mínimo de um núcleo antes de ser explorado; as pedras foram medidas e caracterizadas petrograficamente; os dados obtidos são expostos na Tabela 3.

(1) Dados fornecidos por Walter Neves, Instituto de Biociências Departamento de Biologia, Universidade de São Paulo, que aqui agradecemos pelo apoio.

(2) Os materiais recolhidos são conservados na Fundação Museu do Homem Americano em São Raimundo Nonato. 
Jazidas de rochas silicosas na área do Parque Nacional Serra da Capivara (Piauí, Brasil): primeiros dados geoarqueológicos. R. Museu Arq. Etn., São Paulo, n. 21, p. 103-113, 2011.

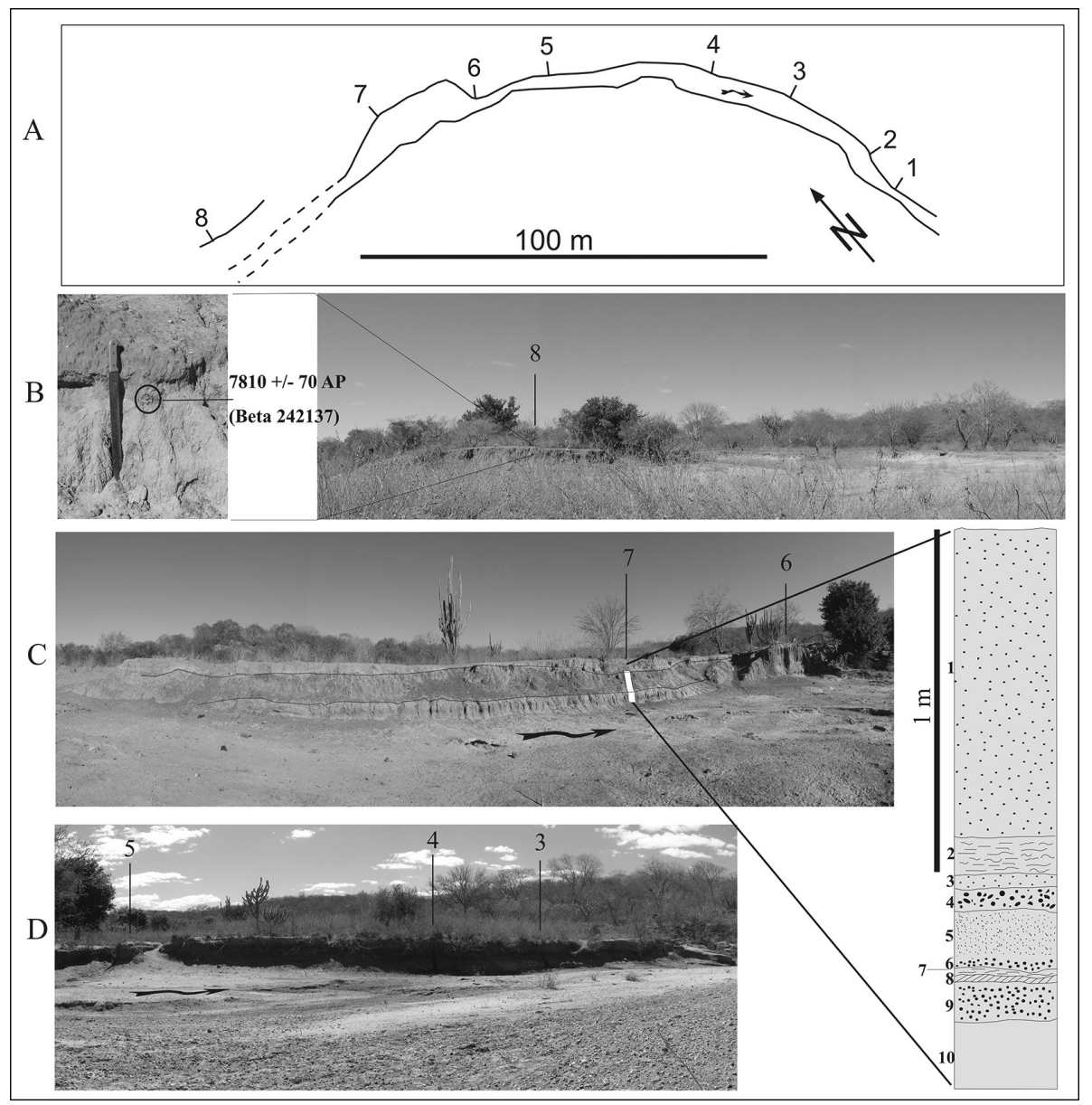

Fig. 3. Terraços RSL.

As porcentagens muito diferentes entre os dois grupos (o da oficina e o das quadrículas) indicam uma preferência evidente pelo sílex, cuja maior aptidão ao lascamento é constatada no instrumentário lítico de muitas jazidas do Holoceno do Nordeste. Na Fig. 5 são mostrados alguns instrumentos em sílex coletados na oficina. A ocorrência do Poço Cavado, apesar de ser a primeira oficina lítica de contexto fluvial estudada na região, provavelmente representa a forma de aproveitamento mais comum de rochas silicosas

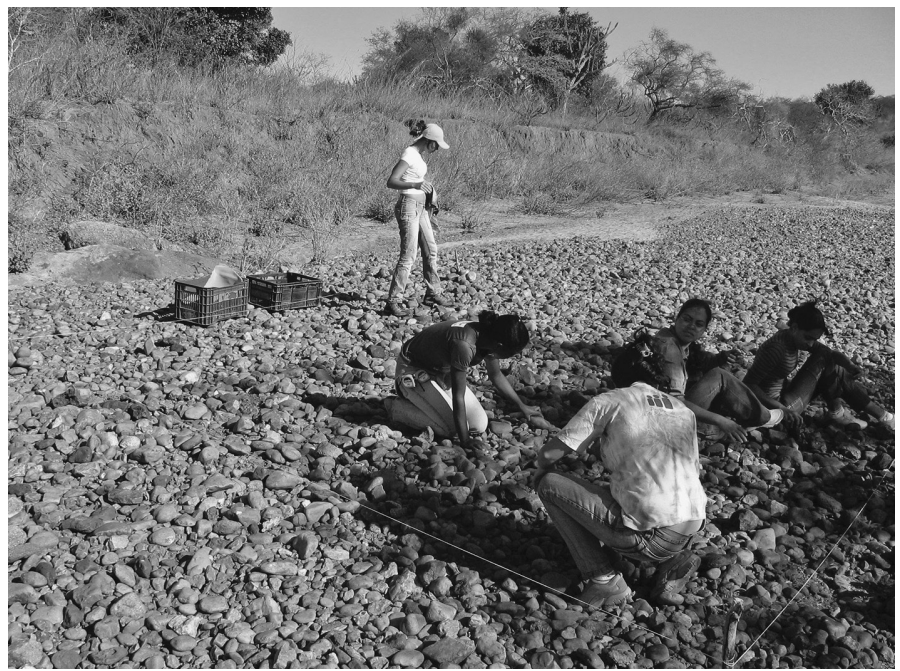

Fig. 4. Poço Cavado. 
Tabela 2

\begin{tabular}{|c|c|c|c|c|c|}
\hline & Quartzito & Quartzo & Sílex & Calcedônia & Tota \\
\hline Núcleo & 2 & & 17 & 5 & 24 \\
\hline Fragmento & 12 & 1 & 62 & 28 & 103 \\
\hline Lasca com córtex & 7 & & 29 & 12 & 48 \\
\hline Lasca sem córtex & & & 10 & 1 & 11 \\
\hline Lasca retocada & & & 12 & & 12 \\
\hline Ferramenta & & & 9 & 3 & 11 \\
\hline Estilhas & & & 1 & & \\
\hline Total & 21 & 1 & 140 & 48 & 210 \\
\hline
\end{tabular}

Tabela 3

\begin{tabular}{|c|c|c|c|c|c|c|}
\hline & \multirow{2}{*}{\multicolumn{2}{|c|}{ Quadr. 1}} & & & \multirow{2}{*}{\multicolumn{2}{|c|}{ Quadr. 1+2 }} \\
\hline & & & \multicolumn{2}{|c|}{ Quadr. 2} & & \\
\hline & Ferramentas & Seixos & Ferramentas & Seixos & Ferramentas & Seixos \\
\hline Calcedônia & 28 & 25 & 18 & 22 & 46 & 47 \\
\hline Quartzito & 13 & 222 & 42 & 73 & 55 & 295 \\
\hline Quartzo & 76 & 5 & & 4 & & 9 \\
\hline Sílex & & 4 & 6 & & 82 & 4 \\
\hline Total & 117 & 256 & 66 & 99 & 183 & 355 \\
\hline \multirow{2}{*}{$\%$} & \multicolumn{2}{|c|}{ Quadr. 1} & \multicolumn{2}{|c|}{ Quadr. 2} & \multicolumn{2}{|c|}{ Quadr. 1+2 } \\
\hline & Ferramentas & Seixos & Ferramentas & Seixos & Ferramentas & Seixos \\
\hline Calcedônia & 23,9 & 9,8 & 27,3 & 22,2 & 25,1 & 13,2 \\
\hline Quartzito & 11,1 & 86,7 & 63,6 & 73,7 & 30,1 & 83,1 \\
\hline Quartzo & & 2,0 & 0,0 & 4,0 & & 2,5 \\
\hline Sílex & 65,0 & 1,6 & 9,1 & 0,0 & 44,8 & 1,1 \\
\hline
\end{tabular}

pelos grupos de caçadores do Holoceno, cujo instrumentário foi sempre observado e descrito a partir de assentamentos em abrigos e grutas, lugares em que a matéria-prima de melhor qualidade, bruta ou em pré-formas, era transportada de fora. ${ }^{3}$

\subsection{Os afloramentos dos maciços calcários}

Desde 1986 os pequenos maciços calcários que bordam as encostas areníticas têm representado o núcleo da pesquisa paleontológica no Sudeste do Piauí. Enquanto a acidez dos depósitos areníticos em abrigo não permite a

(3) Uma amostra de seixos de calcedônia, sílex e quartzito está sendo analisada para uma comparação petrográfica com os líticos e com a matéria-prima de outros sítios e com os materiais silicosos em afloramento (depósitos primários e sub primários). conservação de restos orgânicos além de poucos milênios, as cavidades kársticas a Leste de São Raimundo Nonato têm fornecido muitos dados sobre a fauna de vertebrados do Pleistoceno (Guérin e Faure 2008).

Nos abrigos (como a Toca da Janela da Barra do Antonião, Toca das Moendas), grutas (Toca do Serrote do Artur, Toca do Garricho) e sumidouros (Sumidouro do Sansão) que drapejam as vertentes calcárias são frequentemente encontrados sítios arqueológicos com indústrias líticas de quartzo, sílex e calcedônia. As mesmas matérias-primas, em proporções diferentes, que constituem o recurso mineral dos conjuntos líticos de importantes abrigos com arte rupestre como Pedra Furada, Sítio do Meio, Toca do Perna I. Nesses últimos a calcedônia e sílex são exógenos e, portanto, testemunham a circulação dos grupos e os intercâmbios entre os diferentes ambientes da região. As modalidades dessa circulação, que definem o modelo de assentamento, devem ser pesquisadas através da determinação precisa das fontes de matéria-prima.

Na Pedra Furada, sequência crono-estratigráfica principal da área do PARNA, constatou-se a ausência de sílex e calcedônia nos níveis pleistocênicos (salvo umas poucas peças que prudentemente consideramos esporádicas) enquanto um terço das 6.574 peças das fases Serra Talhada e Agreste é confeccionado em calcedônia, e uma pequena minoria em sílex aparentemente procedente de seixos fluviais que guardam porções de córtex (Parenti 2001). No 

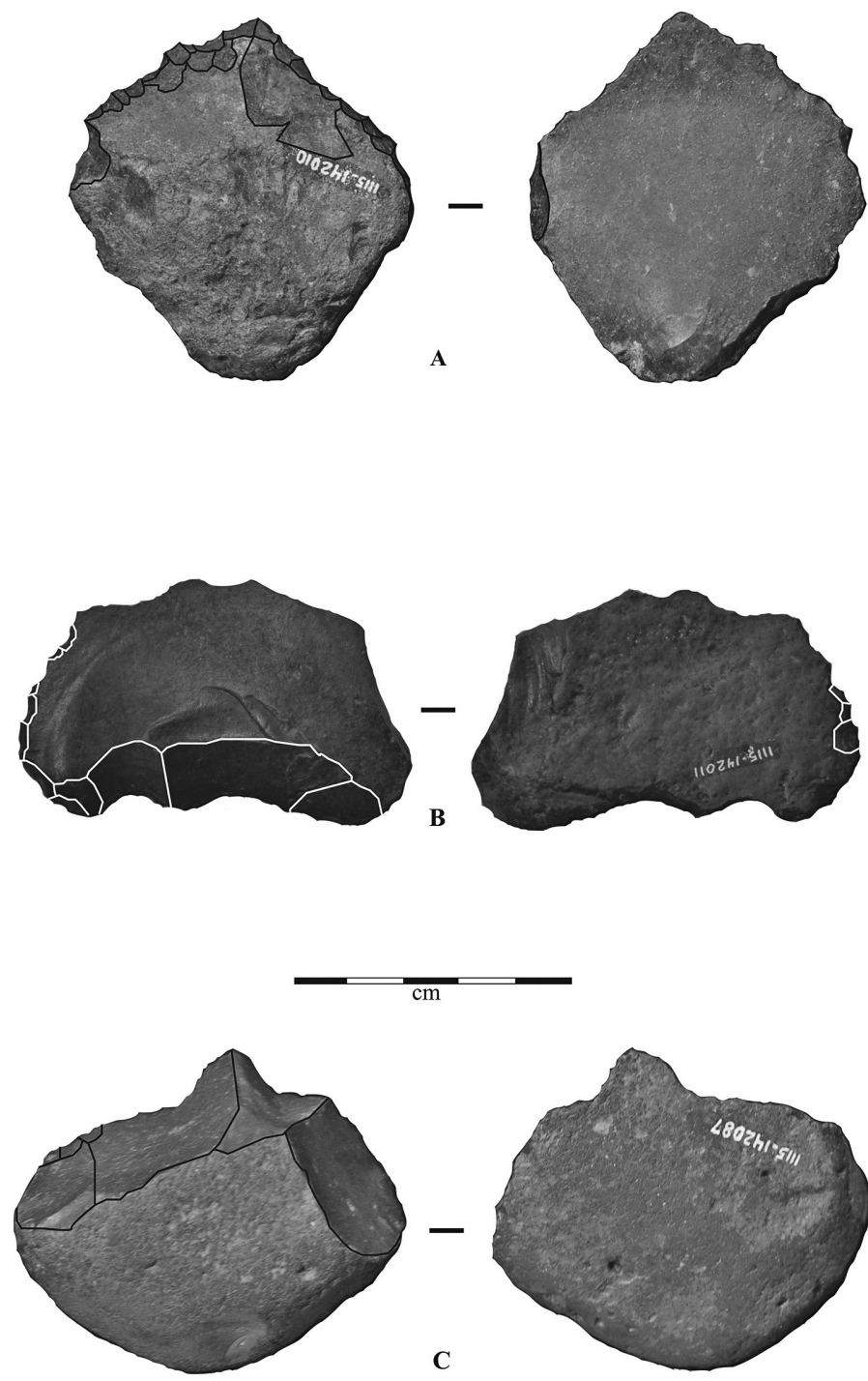

Fig. 5. Líticos.

Sítio do Meio, abrigo arenítico próximo da Pedra Furada com ocupações do Pleistoceno final e da primeira metade do Holoceno, as peças de calcedônia e sílex são ainda mais raras do que na Pedra Furada, só atingindo 2\% no setor 2, o mais importante para o Holoceno inicial (Mota 2010).

Portanto, a determinação petrográfica e geomorfológica das jazidas de procedência é da maior importância para a definição da passagem Pleistoceno-Holoceno na sequência regional.
A partir dessa problemática foi feita a prospecção dos maciços calcários do Grupo Bambuí, Formação Barra Bonita (filitos, xistos, mármores, muscovita quatzitos em fácies anfibolito, de idade 1000-540 Ma - Neoproterozóico-Toniano/Ediacariano), representado pelo serrote que une a Toca de Cima do Pilão ao Sansão e os serrotes da área da Barra do Antonião.

$\mathrm{O}$ resultado mais significativo na área do Serrote do Sansão consiste na individualização de duas concentrações de materiais silicosos. A primeira (Sansão 3, Fig. 1: 5, UTM 23 L 0769347 9020046) é um depósito coluvial com blocos de diversas rochas: calcedônia, sílex e raros quartzitos (Fig. 6).

Subindo para Leste, num pequeno vale rumo a uma selada se encontram blocos de calcedônia preta, às vezes com veias e manchas de sílex brunas e vermelhas (Fig. 7), em matriz argilosa avermelhada (Sansão 1, Fig. 1: 5, UTM 23 L 0769940 9019710).

O contexto e as características petrográficas mesoscópicas indicam que os materiais pertencem ao silcrete ferruginoso que às vezes drapeja as rochas do Pré-Cambriano. Este material, que não possui boa qualidade para o lascamento, é parecido com o de uma parte dos artefatos dos níveis holocênicos do abrigo da Pedra Furada, que fica a $2 \mathrm{~km}$ a Norte.

\subsection{Os afloramentos primários nos arenitos: a Serra do Gongo}

Na região do Gongo, perto do Sítio do Deolindo (Fig. 1: 1, UTM 23 L 0766073 9044636), nos arenitos avermelhados da Formação Cabeça (Arenitos, siltitos arenosos, diamictitos do 


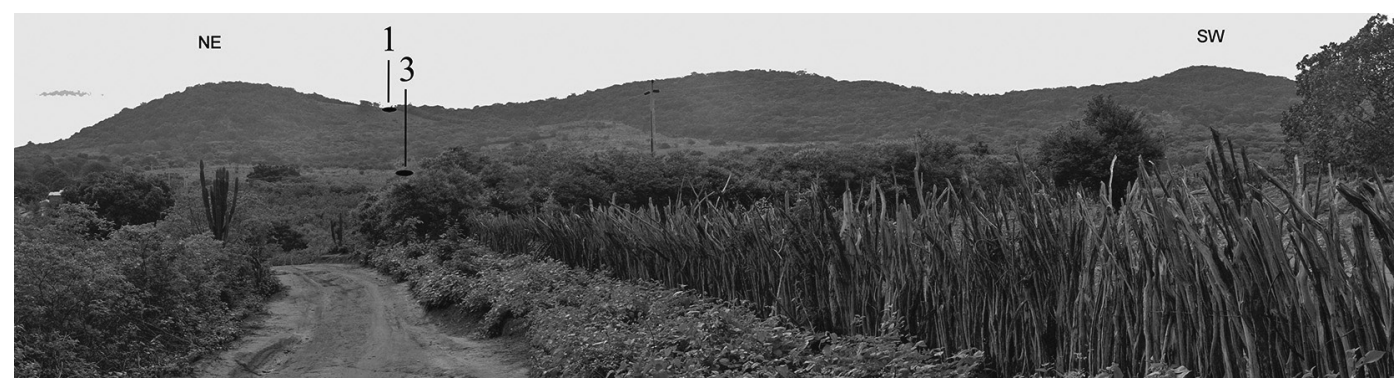

Fig. 6. Serrote Sansão.

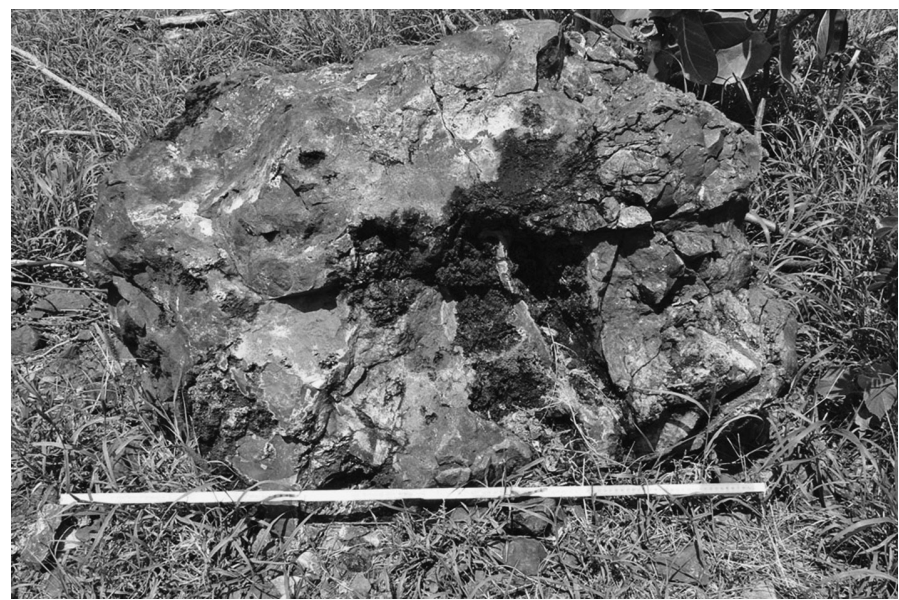

Fig. 7. Afloramento Sansão 1. encosta calcária e aí recorbertos rapidamente durante o Holoceno inicial. Essa dinâmica poderia ser confirmada através de duas medidas: 1) o detalhamento petrográfico de perfis já datados na região (Santos 2007); 2) a execução de algumas sondagens na encosta do preenchimento atual com as vertentes calcárias onde, se houver possibilidade de datação, poder-se-ia esclarecer a relação entre os diferentes lugares frequentados pelos grupos pré-históricos do começo do Holoceno.

Grupo Canindé, 389-375 Ma-Devoniano), folha Rio S.FC ${ }^{\circ}$.NE SC.23-X. CPRM) encontram-se vários seixos quartzíticos distribuídos no arenito ou em cavidades com óxido de ferro e manganês (marmitas de erosão, Fig. 8), talvez exploradas ná pré-história.

\section{Conclusões}

No que diz respeito à ausência de calcedônia nas camadas pleistocênicas da sequência arqueológica regional, a hipótese da invisibilidade das rochas silicosas pode ser aperfeiçoada em termos de que a erosão dos topos dos serrotes calcários tenha começado a se manifestar durante as crises de aridez do Pleistoceno final, quando os solos são desmantelados e os fragmentos de silcrete erodidos provavelmente rolaram ao longo das vertentes até depositar-se na base da

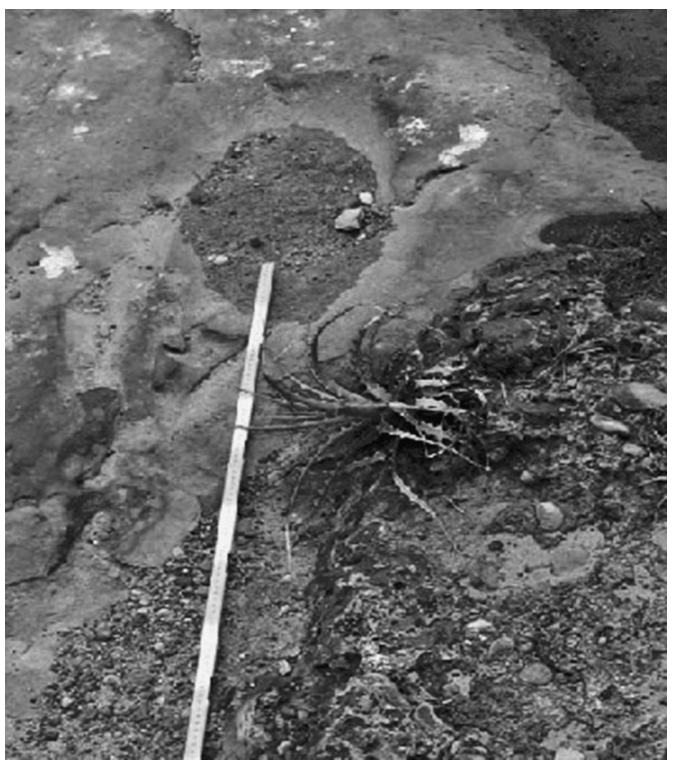

Fig. 8. Marmita de erosão. 


\section{Agradecimentos}

Este trabalho foi possível graças ao apoio da Fundaçao Museu do Homem Americano que aqui agradecemos junto à sua Presidente
Professora Niéde Guidon. A pesquisa foi parcialmente financiada pelo Ministero degli Affari Esteri da Itália em 2007. Agradecemos a Astolfo Araujo e Claude Guérin pelas sugestões.

RIODA, V.; CANDELATO, F.; MOTA, L.; PARENTI, F. Siliceous outcrops in the Serra da Capivara national park (Piaui, Brazil): first geoarchaeological data. $R$. Museu Arq. Etn., São Paulo, n. 21, p. 103-113, 2011.

\begin{abstract}
In lithic prehistoric assemblages from north-eastern Brazil, several siliceous raw materials have been indentified, making their petrographic definition obviously essential for geoarchaeological research. Studies of Holocene layers of Pedra Furada rock-shelter have revealed the importance of raw material economy and circulation in south-eastern Piauí between the late Pleistocene and early Holocene. Nevertheless, until the moment, no geoarchaeological and/or petrographic studies have been carried out on the many siliceous outcrops of the region. In this article, we present the methods and the first geoarchaeological results on 11 archaeological sites or outcrops at the southern fringe of "Serra da Capivara" National Park. Our results show that some types of flint previously considered as being of fluvial origin, are, in fact, derived by in situ alteration of ferrogineous silcrete from pre-Cambrian limestone outcrops. These new data implies in a reconsideration of mobility strategies adopted by pre-ceramic groups in this region.
\end{abstract}

Keywords: Siliceous rocks - Lithic industry - Souteastern Piaui - Geoarchaeology

\title{
Referências bibliográficas
}

ARAUJO, A.G.M.

1991 As rochas silicosas como matéria-prima para o Homen Pré-Histórico: variedades, definições e conceitos. Revista do Museu de Arqueologia e Etnologia, São Paolo, 1: 105-111.

ARAUJO, A.G.M.; PUGLIESE, F.

2008 The use of non-flint raw materials by paleoindians in eastern South America: a Brazilian perspective. In: Sternke, F.; Eigeland, L.; Costa, L.-J. (Eds.) Non-Flint Raw Material Use in Prehistory - Old prejudices and new directions. British Archaeological Reports, 1939: 169-175.
CHAVES, S.A.M.; PARENTI, F.; GUÉRIN, C.; FAURE, M.; CANDELATO, F.; RIODA, V.; MENGOLI, D.; FERRARI, S.; NATALI, L.; SCARDIA, G.; OBERLIN, C.

2008 Palinologicals analyses of Quaternary lacustrine sediments from "Lagoa do Quari”, NE Brazil (Pi). II Simposio internacional O povoamento das Américas, 16-21 déc. 2006, Museu do Homem Americano, Parque Nacional Serra da Capivara, São Raimundo Nonato, Piauí, Brésil. Comunicações, vol. Paleoambiente, paleoclima no pleistoceno das Américas: 1-4. 
GUÉRIN, C.; FAURE, M.

2008 La biodiversité mammalienne au Pléistocène supérieur - Holocène ancien dans la région du Parc National Serra da Capivara (SE du Piauí, Brésil), II Simposio internacional «O povoamento das Américas», São Raimundo Nonato dec. 2006, FUMDHAMentos, 7: 80-93.

GUIDON, N.; PARENTI, F.; LUZ, M.F.; GUERIN, C.; FAURE, M.

1994 Le plus ancien peuplement de l'Amérique: le paleólithique du nordest brésiliene.

Bulletin de la societé Préhistorique Française, 9 (4-5): 246-250.

MAPA GEOLÓGICO 1:250.000, folha Rio S.FC ${ }^{\circ}$.NE SC.23-X .CPRM - Serviço Geologico do Brasil.

Programa recursos hidrícos - Subprograma água subterrânea para a região nordeste Projeto borda sudeste da bacia sedimentar do Parnaíba.

MARTIN, G.

2005 Pré-História do Nordeste do Brasil. Recife: Ed Universitária da UFPE.

MOTA, L.A.

2010 Tecno-tipologia Lítica do Holoceno Inicial
(9.450-8.100 anos BP) do Setor 2 do Sítio do Meio - Parque Nacional Serra da Capivara - PI. São Raimundo Nonato: UNIVASF. (Trabalho de conclusão do curso de Arqueologia e Preservação Patrimonial da Universidade Federal do Vale do São Francisco).

PARENTI, F.

2001 Le gisement quaternaire de la Pedra Furada (Piaui, Bresil). Stratigraphie, chronologie, evolution culturelle. Paris: Ed. Recherches sur les Civilisations.

PARENTI, F.; GUÉRIN, C.; MENGOLI, D.; FAURE, M.; NATALI, L.; CHAVES, S.A.DE M.; FERRARI, S.; VALENÇA, L.M.

2003 Sondagens na Lagoa do Quari, São Raimundo Nonato, Piaui: campanha 2002, FUMDHAMentos, 3: 129-146.

SANTOS, J.C.

2007 O Quaternário do Parque Nacional Serra da Capivara e entorno, Piaui, Brasil: morfoestratigrafia, sedimentologia, geocronologia e paleoambientes. Tese de doutorado, Universidade Federal de Pernambuco, Recife. 
